\title{
Don Manuel Moncloa y Covarrubias, ilustre hombre de Teatro*
}

\author{
$1859-1959$ \\ Por Guillemmo Ugarte Chamorro
}

Al recordarse el día de hoy el primer centenario del nacimiento de don Manuel Moncloa y Covarrubias, el Teatro Universitario de la Universidad Nacional Mayor de San Marcos cumple grato e imperativo deber tributando este sencillo pero fervoroso homenaje a la noble personalidad de tan eminente hombre de teatro que consagró su existencia al cultivo y progreso del arte dramática, Py la la paceiente dyeacueiósoginvestigación de nuestro pasado teatral.

\section{"Jorge Puccinelli Converso"}

Si se pensase por un momento en la mera posibilidad de que en el futuro se ignore o se silencie la batalla, verdaderamente dramática, que desde hace más de diez años se viene librando en el Perú por revitalizar y dignificar la actividad escénica, se experimentaría, seguramente, una clara y penosa sensación de injusticia. Admitido esto, podrá comprenderse la magnitud de la injusticia que entraña el general desconocimiento que en la actualidad padecemos de las pretéritas jornadas histriónicas en las que sucesivas legiones de peruanos ofrendaron sus afanes, sus sueños

* Trabajo leido por su autor en la actuación que, en homenaje al primer centenario del nacimiento de Manuel Moncloa y Covarrubias, ofreció el Teatro Universitario de la Universidad Nacional Mayor de San Marcos el 24 de abril del presente año, en el Salón de Grados de la Facultad de Letros. 
y sus vidas por los mismos ideales que hoy animan a nuestras esforzadas gentes de teatro.

La cabal comprensión de este hecho fue la que inspiró los oportunos homenajes que la Escuela Nacional de Arte Escénico rindió, hace pocos años, a Manuel Ascencio Segura, Felipe Pardo y Aliaga, Carlos Germán Amézaga, Ernestina Zamorano y Leonardo Arrieta, personajes representativos de diversos momentos de esta esencial expresión de nuestra vida cultural.

A tan ilustres nombres es necesario sumar los de muchos otros, especialmente de dramaturgos y actores, cuya apreciable contribución al mantenimiento y lustre del teatro nacional, se halla completamente ignorada o sumida en el más ingrato de los olvidos.

Una de las figuras más injustamente preteridas era la de don Manuel Moncloa y Covarrubias, el otrora popular y querido "Cloamón", seudónimo que utilizó en casi todos sus escritos. Y hasta sarcástico resultaba que aquel que, como ningún otro, había investigado con indesmayable tesón y durante muchos años, en viejos infolios, archivos y bibliotecas, para descubrir y revelar todo género de noticias relativas a sucesos y personajes del arte dramático peruano, no recibiera ni el más modesto recuerdo de la posteridad.

Por eso, el prèsenteod́ctoctienel el cagridulcessabor de la reparación y asume elgygda y bella significación espiritual en cuanto constituye el saludo emocionado y agradecido, que una de las instituciones de la nueva generación peruana de teatro, dedica a la memoria de quien, hace medio siglo, fue unánimemente reconocido como la máxima autoridad del arte escénico en el Perú.

Manuel Moncloa y Covarrubias nació en Lima el 24 de abril de 1859.

Desde muy joven dio muestras de su decidida vocación por las letras y el teatro. A los 18 años publicó un folleto titulado Recreos del pensamiento (1), con prólogo de Nicolás Augusto González. Sus primeros ensayos de autor dramático los hizo en el pequeño teatro que levantó en su propia casa, ubicada en la calle Gremios, y en el que representaban amigos y aficionados. Continuaba así la significativa costumbre limeña - ya desaparecida, por desgracia - de construir y animar este sugestivo tipo de locales llamados teatros caseros, algunos de los cuales alcanza- 
ron renombre, como los que pertenecieron a los doctores Pablo de Olavide, Fernando Casós y José E. Sánchez.

Producida la guerra con Chile, abandonó sus estudios de Derecho y se alistó en el ejército, peleando en la batalla de Miraflores con el grado de Teniente de Reserva. Como diputado por la provincia Dos de Mayo, integró en 1883 la Asamblea Nacional.

Su primera obra teatral impresa fue El nudo (2), ensayo dramático en dos actos que había sido estrenado el 5 de diciembre de 1882 en la incuguración del teatro casero denominado Pepin. Tomaron parte en este estreno los jóvenes aficionados, señoritas Corina y Juana Rosa Cortés y señores José Benigno Ugarte, Samuel Mayer, José Mendiguren y Nicanor de los Ríos.

Con la misma pieza, Moncloa obtuvo su primer éxito internacional : el 25 de noviembre de 1883 fue escenificada por la Sociedad Dramática de la Juventud Cordobesa en el Teatro Principal de Córdoba, España, cludad en la que, poco después, apareció la segunda edición de esta obra primigenia (3).

En 1884 se estrenó públicamente en Lima como autor teatral con el juguete dómico ¿Dos o uno?, representado en el Teatro Politeama por los actores nacionales Ramón Arámbulo y María Barrantes. Este estreno, según refiere el mismo Moncloa, se realizó en circunstancias inesperadas: "Alberto Pérez - dice- a quien habiamios prestado nuestro jugtuete cómico ¿Dos o uno? para que lo leyera, se entendio a la chita callando con la Compañía

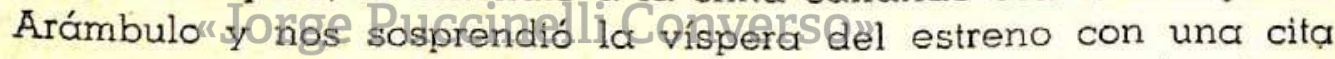
a ensayo general que, velis nolis, nos hacía autor dramático" (4).

Como periodista y autor de artículos de costumbres, colabo. ró en las más prestigiosas publicaciones limeñas con trabajos que continuamente se reproducian en España y las principales capitales latinoamericanas. En 1890 dirigió la revista Ilustración Americana $y$ en 1892, el semanario El Perú Ilustrado.

En 1901 intervino en la organización del Archivo de Límites $y$ tres años después fue nombrado oficial mayor del Archivo del Ministerio de Relaciones Exteriores, cargo desde el que contribuyó eficazmente en la selección de los documentos utilizados en el alegato arbitral del problema de límites con Bolivia. Culminó su carrera en la administración pública ejerciendo la jefatura de la Sección de Contabilidad del mencionado Ministerio.

Pero Moncloa era, esencialmente, un hombre de teatro y un escritor que sólo sentía satisfechas sus más íntimas aspiraciones 
con la creación literaria y la prolija y constante investigación del teatro peruano.

Fue socio fundador del Círculo Literario y miembro del Ateneo de Lima y del Instituto Histórico. Perteneció támbién a numerosas instituciones culturales del extranjero. En el Círculo fue elegido Tesorero pero a los seis meses hizo renuncia del cargo devolviendo, en característico gesto de humor bohemio, los inmaculados recibos, menos los suyos que representaban el único capital de doce soles con que contaba la institución.

La casa de Moncloa fue hogar espiritual de los socios del Círculo Literario. Especialmente los días domingos reuníanse en ella Germán Leguía y Martínez, Abelardo Gamarra, Federico Blume, Pablo Patrón y muchos otros bohemios que derrochaban allí su regocijado ingenio, no siendo pocas las producciones de teatro que nacieron $o$ se dieron a conocer en esas veladas en las que siempre se encontraba, "aparte de la más fraternal y franca acogida, una taza de té, un cubierto, un buem libro y hasta un lecho para el bohemio que no lo tenía" (5).

En 1880 contrajo matrimonio con la distinguida dama doña Clorinda Ordóñez. Tuvo nueve hijos: Manuel, Daniel, Lorenzo, Luis y Joaquín (ya fallecidos) y María Cristina, Luz, Federico y Enrique Moncloa y Ordóñez.

Cuando aún no había cumplido 53 años de edad, Moncloa murió en Lima la tarde del domingo 10 de díciembre de 1911.

Prueba elocuenteg 9 Ponmiovedòra odel chondo afecto que "Cloamón" sintió toda su vida por el historial del teatro peruano, es la nota que desde su lecho de enfermo dirigió a don Jorge M. Corbacho, el 13 de noviembre de 1911, es decir a escasos días de su muerte, solicitándole un ejemplar de la comedia "Los patriotas del día", del autor nacional Enrique León Castellanos, y un manifiesto de doña Rosa Merino, la célebre cantante limeña, piezas que Corbacho le había prometido enviar junto con algunos retratos de cómicos que Moncloa también pedía en su carta postrera (6).

"Cloamón" fue escritor costumbrista, autor teatral $\theta$ historiador de teatro.

Como escritor costumbrista se reveló principalmente en Las Cojinovas y Tipos menudos. Las Cojinovas (7) es una pequeña novela que, en chispearites escenas, refiere las ridículas pretenciones de una familia de "medio pelo". Sus personajes doña Mer- 
cedes y sus hijas Aurora y Emilia son los directos antecedentes de doña Caro y sus hijas Etelvina y Zoraida, las celebradas creaturas del recordado periodista limeño Fausto Gastañeta.

Tipos menudos (8), libro publicado en 1895 con prólogo del poeta y dramaturgo Carlos Germán Amézaga, es una serie de 40 breves y graciosos artículos que pintan personajes y costumbres limeños de fines del siglo pasado. Varios de estos artículos desenvuelven asuntos relativos a la vida teatral, tales como los titulados Una función casera, Áficionado al drama, Apuntes...... (del inglés), Entre literatos, Las bailarinas y El empresario. Mención especial merece Una función casera que describe las divertidas incidencias ocurridas en el hogar de la familia Candel con motivo de representarse el Don Juan Tenorio en celebración del onomástico de la veinteañera Luisita Candel quien, deseosa de hacer rabiar de envidia a sus amigas, había obtenido el consentimiento de su madre para cumplin con la moda imperante en la Lima de entonces, de festejar con funciones caseras los cumpleaños de las niñas llamadas "de sociedad".

Como lo hicierd don Ricardo Palma con los bohemios de su tiempo, Moncloa en su estudio Los bohemios de 1886 (9) se ocu$p a$, en amenos apuntes y recuerdos, de los selectos escritores que en aquel año fundaron el Círculo Literario de Lima cuyos primeros

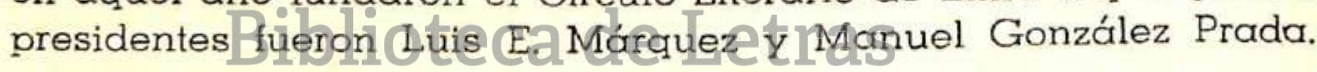

Esta (g’eneración señald uno de dos momentos más importantes de la producción dramática nacional. La mayoría de sus integrantes compusieron una o más piezas escénicas, varias de las cuales conquistaron calurosa aceptación del público y de la crítica. Moncloa, con explicable simpatía, destaca estos éxitos y menciona, entre otros, a los noveles dramaturgos Carlos Germán Amézaga, Luis E. Márquez, Víctor González Mantilla, José Benigno Ugarte, Abelardo Gamarra, José Arnaldo Márquez, Sixto Silva Santisteban, Clorinda Matto de Turner, Hernán Velarde, José Mendiguren, Nicolás Augusto González, Pedro Felipe Revoredo, Germán Leguía y Martínez, Alberto V. Pérez, Oswaldo Carreño Dehesa, Ernesto Rivas, Juan Byron y Julio S. Hernández.

Sensiblemente, y por causas que convendría analizar, esta brillante y nutrida pléyade de jóvenes escritores no perseveraron - salvo escasas excepciones- en el ejercicio de la creación dramática. 
"Cloamón" publicó también Carlos (1884), breve novela, y Costa Rica (1888), libro de recuerdos e impresiones de un viaje que hizo a ese país. Dejó inédita, además, una Historia popular del Perú cuyos originales conforman un legajo de 800 páginas manuscritas. Positiva contribución a la bibliografía histórica nacional, constituiría la publicación de esta voluminosa obra que concluyó en 1908.

Manuel Moncloa y Covarrubias y Felipe Sassone -otro de nuestros autores digno de consideración particular- son, sin duda alguna, los más fecundos dramaturgos peruanos de todos los tiempos. Ni fray Francisco del Castillo, el "Ciego de la Merced", ni Carlos Augusto Salaverry, ni Manuel Ascencio Segura, ni Mariano Isidro Pérez, ni Abelardo Gamarra, ni Ricardo Villarán, prolíficos autores teatrales, superan el caudal de obras compuestas por Moncloa. Estas alcanzan el número de 42, todas representadas y en su mayoría impresers en ediciones agotadas hace ya muchos años. Y debemos advertir que Moncloa escribió varias otras piezas que no dio a la escena ni a la prensa, como las tituladas Después de Miraflores y El candidato, que hemos tenido oportunidad de examinar.

En la historia de nuestra vida literaria, Moncloa constituye, pues, uno de los contados casos de dramaturgos que desarrollaron plenamente su vocadón 110 teca de Letras

Monólogos, revistase saineteis dramas Y epmedias, comprenden la copiosa producción de Moncloa. Sin embargo, fue el género cómico-costumbrista el que cultivó con mayor felicidad.

Su bien disciplinada inteligencia, la asidua lectura de autores extranjeros, la rica experiencia acumulada en los sucesivos estrenos de sus obras, el diario contacto con las gentes de teatro en ensayos y tertulias, y el cabal conocimiento que poseía de los más íntimos secretos de la escena, hicieron de Moncloa un autor de excepcionales condiciones para triunfar.

Los entusiastas aplausos con que el público limeño recibía las creaciones de "Cloamón", obligaron a su reposición decenas de veces. Lima por dentro, compuesta en 1906 en compañía de su hijo Manuel, logró más de cien representaciones consecutivas, hecho sin precedentes tratándose de piezas nacionales. Este extraordinario acontecimiento fue anotado por la crítica como un auspicioso signo del anhelado resurgimiento de la escena peruana. 
Además de Lima por dentro, produjo otras obras en colaboración con escritores nacionales y extranjeros. Citemos, como ejemplos, Los soplones, con Federico Blume; El paraíso perdido, con el poeta y dramaturgo ecuatoriano Nicolás Augusto González; Electra, con Manuel Moncloa y Ordóñez y el actor y comediógrafo portorriqueño Eugenio Astol; $\bar{A}$ media noche y San marido, mártir, con el autor y empresario José Mendiguren; La gran calle, con el poeta tacneño Víctor González Mantilla; y una comedia inédita, con el renombrado médico y también autor teatral peruano Juan M. Byron.

Numerosas comedias de Moncloa se estrenaron también, con notorio éxito, en diversos países americanos.

El desaparecido Servicio de Difusión de la Escuela Nacional de Arte Escénico reeditó hace pocos años, las piezas de Moncloa Resurrección, La primera nube, Sin comerlo ni beberlo y iAl fin solos! Las más recientes representaciones que se hicieron en el Perú de una obra de Moncloa, fueron las que ofrecieron del juguete cómico Sin comerlo ni beberlo, un conjunto de alumnos de la ENAE y el Grupo Teatral Mixto de las dos Grandes Unidades Escolares de la ciudad de Tacna, en 1954 y 1956, respectivamente.

Manuel Moncloa y Ordóñez merece también en esta ocasión nuestro respetuoso $y$-admirativo recuerdo porque fue el heredero de la vocación teatrat de su padre. Fino escritor que popularizó

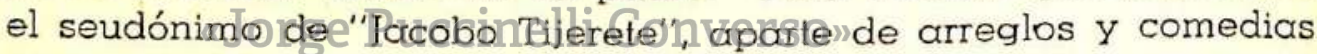
escritas en colaboración con su progenitor, estrenó en sus años mozos afortunadas piezas originales como Plata al diario y Siempre p'alante. Alejado luego de las actividades escénicas, "Jacobo Tijerete" cultivó su reconocida afición a la pintura, siendo altamente estimado en el ambiente artístico limeño como notable coleccionista de cuadros pictóricos.

El famoso y mimado actor cómico peruano Carlos Rodrigo (padre), estuvo íntimamente vinculado a los éxitos teatrales de los Moncloa. La revista Aplausos y Silbidos al comentar en 1906 los triunfos que Rodrigo acababa de obtener en Lima por dentro y Plata al diario, expresaba: "Hay actores que han nacido para interpretar el teatro de tal o cual autor, así vemos a Zaconne, genial intérprete de Ibsen, Rossi de Shakespeare, Vico de Echegaray, María Guerrero de Benavente; nosotros podemos decir sin temor de errar, Rodrigo para los Moncloa" (10). 
Sin desmerecer las calidades de su vasta producción dramática y literaria, consideramos que la obra más valiosa y trascendente de Moncloa fue la que cumplió como el primer serio investigador del arte dramático en el Perú. Nadie antes que él se había preocupado por esta clase de investigaciones. Breves y muy dispersas crónicas periodísticas y volanderas referencias insertas en obras de crítica, literatura o historia, era todo lo que se conocía de nuestra vida farandulera tan rica en sugestiones y en hechos vinculados a nuestro proceso social y cultural y también -con frecuencia poco advertida hasta hoy-a los magnos episodios de la historia patria.

Moncloa comprendió con gran intuición y singular altura de miras, la necesidad de buscar y reunir el mayor número posible de noticias y documentos relativos al teatro peruano para organizarlos, estudiarlos y difundirlos en trabajos que son y serán obligadas fuentes de consulta para los estudiosos de nuestra historia dramática.

A Moncloa le correspondió la tarea pionera de abrir caminos, vencer obstáculos, sufrir incomprensiones, despertar entusiasmos y señalar seguros derroteros para más amplios, eficaces y profundos estudios. Así lo reconoció él mismo cuando escribió: "No creemos haber hecho una obra completa ni exenta de errores; pero al menos somos los primeros en reumir los datos dispersos sobre el teatro en el Perú que servirán mañana de base para quien se ocupe con "más fortuna y aclerto que nosotros, en escribir su historia" (11).

Frutos de tan abnegados esfuerzos, realizados cuando las labores de investigación se desarrollaban en condiciones más penosas aún que las actuales, fueron sus obras De telón adentro. Mujeres de teatro, Diccionario Teatral del Perú y El teatro de Lima.

En De telón adentro (12), publicada por entregas en 1897, Moncloa analiza con aguado sentido de observación y profusión de informaciones, anécdotas y ejemplos, los diferentes momentos del montaje de una pieza escénica y las funciones, características, vicios y virtudes de cada uno de los elementos, principales y secundarios, del complejo teatral. En esta obra, escrita en tono generalmente risueño, el autor denota su extraordinario conocimiento de las intimidades de la escena y de las gentes de la farándula.

Mujeres de teatro (13), se publicó en 1910 y -según las palabras de Clemente Palma, autor del prólogo- "es una galería 
de las damas artistas, discípulas aventajadas de Talía, Melpómene y Terpsicore que han venido por estos barrios, algunas de ellas de reputación mundial tales como la Ristori, Sara Bernhardt, Clara Della Guardia y la Guerrero; desfilan en el libro las principales figuras femeninas teatrales que han hecho reir o llorar a los limeños, desde la Merino que fue la artista que en 1821 entonó por primera vez el himno nacional de Alcedo, hasta la bella y genial Rosario Pino que acaba de llegar. A todas ellas consagra Moncloa capítulos interesantes, sazonados con anécdotas o recuerdos personales".

Atención preferente merecen el Diccionario teatral del Perú y EI Teatro de Lima (14) por ser, indiscutiblemente, los dos mejores aportes de Moncloa a la historia de nuestro teatro.

El Diccionario se publicó en 1905 y contiene, en orden alfabético no siempre regular, los nombres de autores, actores, directores, escenógrafos empresarios, maquinistas, apuntadores, sastres, etc., que actuaron en el Perú desde la época colonial hasta 1904. Hay también importantes noticias sobre locales teatrales de Lima y provincias; teairos caseros; cédulas, edictos y reglamentos correspondientes a representaciones escénicas; estrenos famosos; primeras funciones diurnas, de ópera y de tanda; ocurrencias de entre bastidores; y ruidosos escándalos de artistas y públicos aficionados. teosaérminos, teatrales incluídos (a pesar de

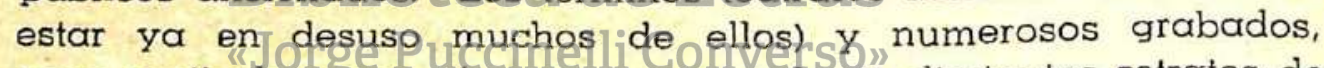
muy particularmente uno que comprende 21 diminutos retratos de otros tantos actores $\mathrm{y}$ actrices peruanos del siglo XIX, contribuyen al mayor valor de esta obra para cuya composición Moncloa consultó nutrida y calificada documentación.

Como muestra del alto aprecio que en los más acreditados centros dramáticos de América se tiene por el diccionario de Moncloa, debemos consignar que en 1947 el Ministerio de Relaciones Exteriores y Culto de la República Argentina logró obtener, mediante gestiones especiales, un ejemplar de dicha obra a fin de donarlo a la Biblioteca del Instituto Nacional de Estudios de Teatro, de Buenos Aires. El prestigioso Boletín de esta última institución dio cuenta de la donación en un destacado artículo que, ilustrado con las fotografías de Moncloa y de la portada del preciado libro, llevó el ufano título de "El Diccionario Teatral del Pe. rú de Manuel Moncloa y Covarrubias en nuestra Biblioteca Pública" (15). 
Con motivo de la inauguración del Teatro Municipal (hoy Teatro Segura) apareció en 1909 El Teatro de Lima. En él Moncloa se propuso dar una "ligera idea - son sus propias palabras- de la evolución del teatro entre nosotros en el largo lapso de casi tres centurias; desde los autos sacramentales declamados a todo pulmón en las plazuelas y atrios de las iglesias por groseros histriones o mulatos aficionados, hasta las aristocráticas audiciones líricas y representaciones clásicas de las eminencias europeas en nuestros modestos coliseos".

Son particularmente interesantes las informaciones que contiene acerca de las primeras representaciones habidas en plazas públicas y corrales de comedias; del teatro de San Agustín y del que Alonso de Avila estrenó en 1662 en el tradicional lugar en que ahora se levanta el Teatro Segura; de las funciones palaciegas y de la comedia El mejor escudo de Perseo escrita por el virrey del Perú, Marqués de Castell dos Ríus; de los primeros farsantes; de la genial "Perricholi"; del estreno del Himno Nacional; de los primeros autores y actores peruanos; de la censura teatral; y de las principales compañias que han actuado en Lima desde 1604 hasta 1908.

En la bibliografía nacional, El teatro de Lima es el único estudio integral, aunque sucinto, del proceso histórico de la escena limeña.

Con generoso $\mathrm{y}$ patriótico afán. Moncloa también difundió en el extranjero las actividades del featro peruano. "Gracias a su diligente labor como corresponsal de la excelente revista madrileña El Teatro, la afición española y latinoamericana estuvo periódicamente informada, en los primeros años del presente siglo, de los más significativos sucesos ocurridos en los tablados limeños de la época.

Pocos días después de la muerte de "Cloamón" apareció en el diario La Prensa un artículo recordatorio firmado con el seudónimo de "Carlos Severo". En él se cuenta la siguiente anécdota:

"Una tarde a mediados de diciembre de 1907, encontró (Moncloa) un documento de alta importancia, y comunicó el hecho al Ministro. Dos días después el oficial mayor, felicitando a Moncloa por el hallazgo, le solicitó con urgencia el legajo. Fué a buscarlo don Manuel, y con harta sorpresa vió que no estaba donde 
lo había guardado. Y allí fueron los apuros. Seis horas pasó buscando el viejo expediente, sofocado y nervioso, hasta que por fin logró hallarlo en una caja puesta en lo alto de la estantería del archivo. ¿Quién lo puso allí? Eso no se logró saber jamás. Pero el hecho es que en aquella búsqueda pasó muy desagradables ratos.

"Cuando volvió de entregar al ministro el documento, un compañero de oficina le dijo:

- Suerte ha tenido, don Manuel, en encontrarlo.

- ¿Suerte ésa?..... Suerte será la que me voy a sacar si encuentro un billete de lotería con las tres últimas cifras iguales al número de orden de ese legajo.......

$\mathrm{Y}$ púsose a buscar ese billete, encargándolo a porteros $\mathrm{Y}$ amigos.

Al fin logró hallarlo y lo compró.

Desde ese día fué el tema de todas las charlas la lotería famosa. El tenía que ganarla; no cabía duda.

Y llegó la tarde de pascua, que se jugaba la zarandeada lotería.

Don Manuel, sentado al pie de su escritorio, estaba engolfado en su labor de clasificación. De pronto, a cosa de las cinco y media, soblicitabådhablar con él unat-persona urgentemente. Sale don Manuel, y a poco regresa rozagante de felicidad.

Un companero fe asalta: Converșo"

- ¿Y.... buena noticia don Manuel?

-Por supuesto.

- ¿Acertó usted....?

- Acerté.... Un momento; voy a comparar.

Don Manuel se dirigió a su escritorio y el empleado echó a correr la noticia por las oficinas :

Don Manuel se había sacado la suerte, en ese momento la estaba comparando...." licitarlo.

Aquello fué una avalancha. Todo el personal acudió a fe-

-Que sea enhorabuena, don Manuel....

-Gracias, hombre, gracias, pero no es para tanto escán-

-¿Qué, no ha sido el Gordo? 
- Precisamente, el gordo Pérez (*) me lo ha traído.

-¿Qué anuncio?

-¿Qué anuncio? El original.

- ¿El original de qué?

-De una petipieza escrita de puño y letra del virrey Amat, para una fiesta de la Perricholi.

-Pero, y la suerte de hoy....

- No ha sido floja. Acabo de comparar la letra y no me cabe duda, es del propio virrey. Amat.

- Tableau!

"La lotería de navidad no le había preocupado en lo menor aquel día. Entusiasmado por el teatro y su historia, él estaba feliz con su hallazgo de esa petipieza, mientras todos los empleados de la oficina sólo pensaban en el billete de lotería, con los números famosos que, desde luego, se quedaron en la "bola" (16).

La anécdota transcrita demuestra el carácter bonachón de "'Cloamón" y, sobre todo, su apasionlada, obsesiva, preocupación por cuanto se relacionase con el teatro nacional. Pero contiene, además, la interesantísima noticia del descubrimiento de una pieza teatral manuscrita, compuesta especialmente por el virrey Amat y Junient para Miquita Villegas, la "Perricholi".

Ninguno de los muchos y autorizados escritores nacionales y extranjeros que \$eihan oxupada debvirrey Amat y de la fascinante figura de la celebre comica perulera, se refiere a obra alguna de teatro escrifar por Almat. eY no deja sopprender que el propio "Cloamón" en su estudio sobre El Teatro de Lima publicado a principios de 1909, o sea a poco más de un año del hallazgo consignado por "Carlos Severo", tampoco haga mención, en los párrafos que dedica al virrey y su amante, a tan curiosa petipieza.

Sin embargo, los detalles que proporciona "Carlos Severo" tienen todos los visos de verosimilitud, por lo que, contando con la colaboración de los dignos descendientes de "Cloamón", convendría estudiar las posibilidades de verificar tan importante hecho.

De comprobarse la existencia del manuscrito en cuestión, la literatura dramática nacional podría enorgullecerse de contar con una nueva pieza de inapreciable valor.

(*) Leopoldo Pérez, literato y autor dramático. 
Hay, en cambio, absoluta certeza de que Moncloa poseyó un rarísimo ejemplar impreso de El mejor escudo de Perseo, obra teatral escrita en Lima por el virrey del Perú Marqués de Castell dos Ríus, en celebración del nacimiento del Príncipe de Asturias, el futuro Luis I de España. Esta "comedia harmónica" como la calificó su autor por llevar intercalados algunos números musicales, se representó el 17 de setiembre de 1708 en un esplendente teatro erigido en el patio del palacio virreinal.

En El teatro de Lima Moncloa publicó el facsimile de la portada de esta comedia y anotó: "El raro ejemplar que poseemos, impreso a 2 columnas, en folio mayor, consta de 20 páginas y tiene una corrección hecha, a lo que parece, de mano del propio virrey" (17).

Lohmann Villena en su fundamental obra El arte dramático en Lima durante el virreinato, al ocuparse del impreso que Moncloa tuvo en su poder, escribió "vanas han sido mis diligencias para averiguar el paradero actual de pieza tan valiosa para la historia del teatro en el Nuevo Mundo" (18).

El centenario que hoy celebramos invita y obliga cordialmente a reanudar la necesaria búsqueda que ojalá conduzca al feliz hallazgo de esta preciosa joya de nuestro rumboso teatral colonial.

Tales fueron la vida y la obra del inteligente, culto y labo-

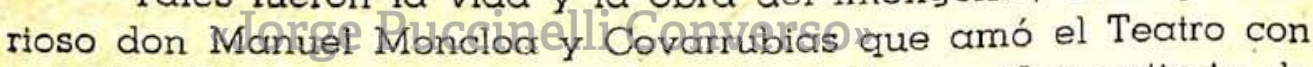
indeclinable y ejemplar devoción. Y el Teatro Universitario de la antigua y gloriosa casa de San Marcos le rinde este vivo y justiciero homenaje porque desea que, además de bella, sea también cierta la frase que dice "amor con amor se paga", y porque la gratísima memoria de "Cloamón". reafirma y fortalece nuestra fe en la creciente prosperidad y en la futura grandeza del Teatro Peruano.

\section{B I B L I O G R A F I A}

(1) Moncloa y Covarrubias, Manuel, Recreas del pensamiento, Lima, Imp. del Teatro, Portal de San Agustín No 82 y 84, 1877.

(2) Moncloa y Covarrubias, Manuel, El nudo, ensayo dramático en dos actos y en prosa, Lima, Lit. e Imp. Antigua Calle del Correo No 42, 1883.

(3) Moncloo y Covarrubias, Manuel, EI nudo, segunda edición, Córdoba (España), Imp., Lib. y Lit. del "Diario de Córdoba", San Fernando 34 y Letrados $18,1884$. 
(4) Moncloa y Covarrubios, Manuel (Cloamón), Diecionario teatral del Perú, Lima, Lit. y Tip. de Badiola y Berrio, editores, Unión (Baquijano) 784, 1905, p. 23.

(5) Diario "La Prensa', Buenos Aires, diciembre de 1911.

(6) Carta en poder de los familiares de Manuel Moncloa y Covarrubias.

(7) Moncloo y Covarrubias, Manuel (Cloamón), Las Cojinovas, costumbres limeñas.... cursis, prólogo de don José Santos Chocano, dibujos de Cachy y Narváez, Lima, Bodiola y Berrio ,editores, Lit. e Imprenta, calle de Baquíjano 784, 1905.

(8) Moncloa y Covarrubias, Manuel, Tipos menudos, prólogo de Carlos Germán Amézaga, Lima, Carlos Prince editor, Imprenta y Librería del Universo $75,1895$.

(9) Moncloa y Covarrubias, Manuel, Los bohemios de 1886, lapuntes y recuerdos), Lima, Guillermo Stolte editor, Imp. y Lib. Melchormalo 125128-130, 1901.

(10) Aplausos y Silbidos, semanario de teatros, foros y sport, Lima, oño I, No 8, 15 de setiembre de 1906, p. 109.

(11) Diccionario teatral del Perú. ..... p. 2.

(12) M. M. y C., De telón adentro, Lima, Imprenta del Estado, Rifa 58, 1897.

(13) Moncloa y Covarrubios, M. (Cloamón), Mujeres de teatro (apuntes personales y recuerdos), prólogo de Clemente Paimo, Callao, Imp. El Progreso, Gálvez 41 y Libertad 56, 1910.

(14) Moncloa y Covarrubios, M. (Cloamón), El teatro de Lima, Lima, Librería e Imprenta Gil, Banco de Herrador Nos. 569 a 579, 1909.

(15) Boletin de Estudios de Teatro, Instituto Nacional de Estudios de Teatro, Comisión Nacional de Cultura, Buenos Aires, Año V, tomo V, No 16, marzo, 1947, pp. 61- 63.

(16) Diario "La Prensa", Lima, 7 de diciembre de 1911.

(17) El teatro de Lima. Ó. T. p. 22.2. de etras

(18) Lohmann Villena, Guillermo, El arte dramático en Lima durante el virreinato, Madrid, "Estodes, artes Gráficas, Evaristd/Sans Miguel, 8, 1945, p. 326. 